\title{
Long-term observation of mass-independent oxygen isotope anomaly in stratospheric $\mathrm{CO}_{2}$
}

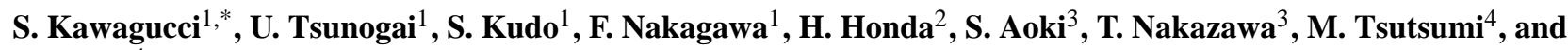 \\ T. Gamo \\ ${ }^{1}$ Earth and Planetary System Sciences, Faculty of Science, Hokkaido University, Sapporo, Japan \\ ${ }^{2}$ Japan Aerospace Exploration Agency, Sagamihara, Japan \\ ${ }^{3}$ Center for Atmospheric and Oceanic Studies, Graduate School of Science, Tohoku University, Sendai, Japan \\ ${ }^{4}$ Dept. of Chemical Oceanography, Ocean Res. Ins., Univ. of Tokyo, Nakano-ku, Tokyo, Japan \\ *present address: Dept. of Chemical Oceanography, Ocean Res. Ins., Univ. of Tokyo, Nakano-ku, Tokyo, Japan
}

Received: 9 October 2007 - Published in Atmos. Chem. Phys. Discuss.: 9 November 2007

Revised: 4 April 2008 - Accepted: 8 September 2008 - Published: 24 October 2008

\begin{abstract}
Stratospheric and upper tropospheric air samples were collected during 1994-2004 over Sanriku, Japan and in 1997 over Kiruna, Sweden. Using these archived air samples, we determined the triple oxygen-isotope composition of stratospheric $\mathrm{CO}_{2}$ and the $\mathrm{N}_{2} \mathrm{O}$ mixing ratio. The maximum $\Delta{ }^{17} \mathrm{O}_{\mathrm{CO}_{2}}$ value of $+12.2 \%$, resembling that observed previously in the mesosphere at $60 \mathrm{~km}$ height, was found in the middle stratosphere over Kiruna at $25.6 \mathrm{~km}$ height, suggesting that upper stratospheric and mesospheric air descended to the middle stratosphere through strong downward advection. A least-squares regression analysis of our observations on a $\delta^{18} \mathrm{O}_{\mathrm{CO}_{2}}-\delta^{17} \mathrm{O}_{\mathrm{CO}_{2}}$ plot $\left(r^{2}>0.95\right)$ shows a slope of $1.63 \pm 0.10$, which is similar to the reported value of $1.71 \pm 0.06$, thereby confirming the linearity of three isotope correlation with the slope of 1.6-1.7 in the mid-latitude lower and middle stratosphere. The slope decrease with increasing altitude and a curvy trend in three-isotope correlation reported from previous studies were not statistically significant. Using negative linear correlations of $\Delta^{17} \mathrm{O}_{\mathrm{CO}_{2}}$ and $\delta^{18} \mathrm{O}_{\mathrm{CO}_{2}}$ with the $\mathrm{N}_{2} \mathrm{O}$ mixing ratio, we quantified triple oxygen-isotope fluxes of $\mathrm{CO}_{2}$ to the troposphere as $+48 \%$ o $\mathrm{GtC} / \mathrm{yr}\left(\Delta^{17} \mathrm{O}_{\mathrm{CO}_{2}}\right)$ and $+38 \%$ o $\mathrm{GtC} / \mathrm{yr}\left(\delta^{18} \mathrm{O}_{\mathrm{CO}_{2}}\right)$ with $\sim 30 \%$ uncertainty. Comparing recent model results and observations, underestimation of the three isotope slope and the maximum $\Delta^{17} \mathrm{O}_{\mathrm{CO}_{2}}$ value in the model were clarified, suggesting a smaller $\mathrm{O}_{2}$ photolysis contribution than that of the model. Simultaneous observations of $\delta^{18} \mathrm{O}_{\mathrm{CO}_{2}}, \delta^{17} \mathrm{O}_{\mathrm{CO}_{2}}$, and $\mathrm{N}_{2} \mathrm{O}$ mixing ratios can elucidate triple oxygen isotopes in $\mathrm{CO}_{2}$ and clarify complex interactions among physical, chemical, and photochemical processes occurring in the middle atmosphere.
\end{abstract}

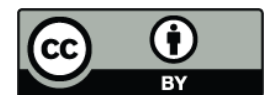

Correspondence to: S. Kawagucci (kawagucci@ori.u-tokyo.ac.jp)

\section{Introduction}

The value of $\delta^{17} \mathrm{O}$, (defined as $\left[\left({ }^{17} \mathrm{O} /{ }^{16} \mathrm{O}\right)_{\text {sample }} /\right.$ $\left.\left({ }^{17} \mathrm{O} /{ }^{16} \mathrm{O}\right)_{\text {VSMOW }}-1\right] \times 1000(\%)$, where VSMOW is an international oxygen isotope standard) varies during many isotopic fractionation processes, but the relation between $\delta^{17} \mathrm{O}$ and $\delta^{18} \mathrm{O}$ values is usually conserved according to the mass-dependent relation of $\delta^{17} \mathrm{O}=0.516 \times \delta^{18} \mathrm{O}$ (Matsuhisa et al., 1978; Santrock et al., 1985). Mass-independent triple oxygen-isotopic fractionation processes, which engender a non-zero value of $\Delta^{17} \mathrm{O}\left(=\delta^{17} \mathrm{O}-0.516 \times \delta^{18} \mathrm{O}\right)$, so-called ${ }^{17} \mathrm{O}$ anomaly, have been found in several chemical reactions, such as in the photochemical production of $\mathrm{O}_{3}$ from $\mathrm{O}_{2}$ (Thiemens and Heidenreich, 1983; Mauersberger, 1987). Note that this equation is an often-used linearization as described for example in Young et al. (2002), Miller et al. (2002), and Miller et al. (2007).

Tropospheric $\mathrm{CO}_{2}$ has an almost constant $\delta^{18} \mathrm{O}$ value $\left(\sim+41 \%\right.$ o) with a small ${ }^{17} \mathrm{O}$ anomaly which results from rapid oxygen isotope exchange between tropospheric $\mathrm{CO}_{2}$ and surface water such as leaf water and seawater (Thiemens et al., 1991; Ciais et al., 1997; Hoag et al., 2005). In contrast, anomalously high $\delta^{18} \mathrm{O}$ values and a positive ${ }^{17} \mathrm{O}$ anomaly have been observed in stratospheric $\mathrm{CO}_{2}$ over Texas and New Mexico (Thiemens et al., 1991), in southern high-latitude regions (Thiemens et al., 1995a), over Sanriku in Japan (Gamo et al., 1989;, 1995; Aoki et al., 2003; Kawagucci et al., 2005), over Kiruna in Sweden (Alexander et al., 2001; Lämmerzahl et al., 2002), Aire-sur-l'Adour in France (Lämmerzahl et al., 2002), in northern high-latitudinal regions (Boering et al., 2004), and also in the upper stratosphere and lower mesosphere over New Mexico (Thiemens et al., 1995b). The ${ }^{17} \mathrm{O}$ anomaly observed for middle atmospheric (stratospheric and mesospheric) $\mathrm{CO}_{2}$ is generally thought to be derived from a

Published by Copernicus Publications on behalf of the European Geosciences Union. 
series of chemical reactions of which $\mathrm{O}_{3}$ formation is the principal source of extra heavy $\delta^{18} \mathrm{O}$ and $\Delta^{17} \mathrm{O}$ (Mauersberger, 1987; Yung et al., 1991; Lacoursiere et al., 1999; Perri et al., 2003):

$$
\begin{array}{r}
\mathrm{O}_{3}+h v(<310 \mathrm{~nm}) \rightarrow \mathrm{O}_{2}+\mathrm{O}\left({ }^{1} \mathrm{D}\right) \\
\mathrm{O}_{2}+h v(<175 \mathrm{~nm}) \rightarrow \mathrm{O}\left({ }^{3} \mathrm{P}\right)+\mathrm{O}\left({ }^{1} \mathrm{D}\right) \\
\mathrm{CO}_{2}+\mathrm{O}\left({ }^{1} \mathrm{D}\right) \rightarrow \mathrm{CO}_{3}^{*} \rightarrow \mathrm{CO}_{2}+\mathrm{O}\left({ }^{3} \mathrm{P}\right) \\
\text { or } \mathrm{CO}_{2}+\mathrm{O}\left({ }^{1} \mathrm{D}\right)
\end{array}
$$

In addition to those field observations, several laboratory experiments and model calculations have been conducted to elucidate detailed mechanisms of mass-independent oxygen isotope fractionation of $\mathrm{CO}_{2}, \mathrm{O}_{3}$, and $\mathrm{O}_{2}$ in the middle atmosphere (Wen and Thiemens, 1993; Johnston et al., 2000; Chakraborty and Bhattacharya, 2003; Liang et al., 2007; Shaheen et al., 2007). In addition, the flux of oxygen anomaly in $\mathrm{CO}_{2}$ from the stratosphere to the troposphere is an important parameter for the tropospheric $\mathrm{CO}_{2}$ budget, which is useful to investigate carbon circulation between the atmosphere and the biosphere (Cuntz et al., 2003; Boering et al., 2004; Hoag et al., 2005).

Although several observational studies have revealed anomalous oxygen isotopic compositions in stratospheric $\mathrm{CO}_{2}$, few samples or parameters have been obtained for each observation, rendering further detailed quantitative analyses difficult. For example, some reports have presented results from fewer than 10 stratospheric air samples (Thiemens et al., 1991, 1995a; Alexander et al., 2001). In more extensive studies, interesting correlations have been reported for the lower stratosphere of $\delta^{18} \mathrm{O}_{\mathrm{CO}_{2}}-\delta^{17} \mathrm{O}_{\mathrm{CO}_{2}}$ (Lämmerzahl et al., 2002), $\delta^{18} \mathrm{O}_{\mathrm{CO}_{2}}-\mathrm{N}_{2} \mathrm{O}$ mixing ratio (Aoki et al., 2003), and $\Delta{ }^{17} \mathrm{O}_{\mathrm{CO}_{2}}-\mathrm{N}_{2} \mathrm{O}$ mixing ratio (Boering et al., 2004). However, no report has described a comprehensive dataset to elucidate these unique relations in the same observation, which hinders further comparison of direct data to modeling studies.

The correlation plot between $\delta^{18} \mathrm{O}$ and $\delta^{17} \mathrm{O}$ is useful to discuss mass-independent isotope fractionation processes because vertical deviation from a terrestrial fractionation line (TFL: slope $=0.516$ ) corresponds to the ${ }^{17} \mathrm{O}$ anomaly. Several previous studies of the triple oxygen isotope composition of middle atmospheric $\mathrm{CO}_{2}$ have revealed a linear correlation between $\delta^{18} \mathrm{O}$ and $\delta^{17} \mathrm{O}$. However, slopes of the linear correlation lines and the degree of the mutual relation differ among studies. For example, Lämmerzahl et al. (2002) reported a close linear relation with a slope of $1.71 \pm 0.06(2 \sigma)$ in the lower/middle stratosphere air over Aire-sur-l'Adour $\left(44^{\circ} \mathrm{N}\right)$ and Kiruna $\left(68^{\circ} \mathrm{N}\right)$; in contrast, Thiemens et al. (1995b) reported a slope of $1.18 \pm 0.17$ for the upper stratosphere/lower mesospheric air over New Mexico $\left(32^{\circ} \mathrm{N}\right)$. This difference in slope was interpreted as a gradual decrease in slope occurring concomitantly with increasing altitude (Kawagucci et al., 2005; Liang et al., 2007), although such a change in slopes has not been observed to date.
As described in this paper, we report triple oxygen isotope compositions of $\mathrm{CO}_{2}$ and its relation with the $\mathrm{N}_{2} \mathrm{O}$ mixing ratio of the middle-latitude lower/middle stratospheric $\mathrm{CO}_{2}$ samples collected during 11 years' air sampling over Sanriku, Japan and Kiruna, Sweden. The long-term stratospheric air sampling program over Sanriku was started in 1985 (Gamo et al., 1989). It continued during 1994-2004, while additional stratospheric air sampling was carried out over Kiruna in February 1997 within the polar vortex. Oxygen isotope fluxes in $\mathrm{CO}_{2}$ from the stratosphere to the troposphere and triple oxygen isotope fractionation processes in the middle atmosphere are discussed using the comprehensive dataset of triple oxygen isotope composition of stratospheric $\mathrm{CO}_{2}$ and the mixing ratio of $\mathrm{N}_{2} \mathrm{O}$.

\section{Sampling and analysis}

\subsection{Sampling and sample storage}

Stratospheric whole air samples were collected during six balloon flights over Sanriku, Japan $\left(39^{\circ}\right.$ N, Table 1) during 1994-2004 using a balloon-borne cryogenic sampler developed by the Japan Aerospace Exploration Agency (JAXA). Using the same sampling system, additional vertical sampling was carried out at Kiruna, Sweden $\left(68^{\circ} \mathrm{N}\right)$ on $22 \mathrm{Febru}-$ ary 1997 (Table 1). Details of our air sampler and sampling procedure have been reported elsewhere (Nakazawa et al., 1995; Honda et al., 1996; Aoki et al., 2003; Honda, 2001). Herein, we describe them briefly. The air sampling system can collect multiple whole-air samples into pre-evacuated $760 \mathrm{~cm}^{3}$ stainless steel sample bottles. Chemical and isotopic compositions in the sampled air are only slightly affected by the collection process (Honda et al., 1996; Honda, 2001). Preliminary experimental tests showed that a possible change of $\delta^{18} \mathrm{O}_{\mathrm{CO}_{2}}$ caused by isotope exchange between $\mathrm{CO}_{2}$ and water on the inner walls of the sample bottle is comparable to our analytical precision of $0.05 \%$ (Honda, 2001; Gamo et al., 1995; Aoki et al., 2003). For $\Delta{ }^{17} \mathrm{O}_{\mathrm{CO}_{2}}$, such preliminary experimental tests were not carried out, but we consider that this sampling process also provides results within our analytical precision of $0.5 \%$, as discussed previously (Boering et al., 2004).

In the laboratory, each whole air sample in the stainless steel bottle of the sampler was divided into several aliquots. From each aliquot, $\mathrm{CO}_{2}$ was extracted and separated from water vapor and other components using cryogenic trapping, which is commonly used in $\mathrm{CO}_{2}$ isotope analysis. The separated $\mathrm{CO}_{2}$ gas was then sealed into a glass ampoule that had been combusted at $400^{\circ} \mathrm{C}$ and kept in a desiccator to avoid contamination by water and organic matter. These $\mathrm{CO}_{2}$ samples had been stored for more than a decade before current isotope analysis. Although the storage period is quite long, the change in $\delta^{18} \mathrm{O}_{\mathrm{CO}_{2}}$ is expected to be negligible because very little water remains in the ampoules. 
Table 1. Measured oxygen isotopic compositions of $\mathrm{CO}_{2}$ are shown with the sampling location, date, altitude, and $\mathrm{N}_{2} \mathrm{O}$ mixing ratio. A sample denoted with \# is regarded as mesosphere-derived air. Five samples marked with * are regarded as tropospheric air. Errors of $\delta^{18} \mathrm{O}$, $\delta^{17} \mathrm{O}$, and $\Delta^{17} \mathrm{O}$ are estimated respectively as at most, $0.05 \%, 0.5 \%$, and $0.5 \%$.

\begin{tabular}{|c|c|c|c|c|c|c|c|}
\hline Location & Date & $\begin{array}{l}\text { Altitude } \\
(\mathrm{km})\end{array}$ & $\begin{array}{c}\mathrm{N}_{2} \mathrm{O} \\
(\mathrm{ppbv})\end{array}$ & $\begin{array}{c}\delta^{18} \mathrm{O} \\
(\% o)\end{array}$ & $\begin{array}{c}\delta^{17} \mathrm{O} \\
(\% o)\end{array}$ & $\begin{array}{r}\Delta^{17} \mathrm{O} \\
(\% o)\end{array}$ & \\
\hline \multirow{47}{*}{$\begin{array}{l}\text { Sanriku } \\
\left(39^{\circ} \mathrm{N}\right)\end{array}$} & \multirow[t]{8}{*}{31 Aug 94} & 18.2 & 289 & 41.89 & 22.6 & 1.0 & \\
\hline & & 20.4 & 266 & 42.29 & 23.2 & 1.4 & \\
\hline & & 22.3 & 196 & 43.22 & 24.9 & 2.6 & \\
\hline & & 24.7 & 158 & 43.67 & 25.8 & 3.3 & \\
\hline & & 26.8 & 135 & 43.75 & 25.6 & 3.0 & \\
\hline & & 29.2 & 127 & 43.50 & 25.7 & 3.2 & \\
\hline & & 31.1 & 92 & 44.29 & 27.8 & 5.0 & \\
\hline & & 34.7 & 72 & 44.75 & 27.6 & 4.5 & \\
\hline & \multirow[t]{8}{*}{8 Jun 95} & 20.3 & 209 & 43.67 & 24.8 & 2.3 & \\
\hline & & 22.3 & 223 & 41.92 & 23.1 & 1.4 & \\
\hline & & 24.5 & 129 & 45.35 & 28.1 & 4.7 & \\
\hline & & 26.7 & 108 & 45.21 & 27.9 & 4.5 & \\
\hline & & 28.8 & 66 & 46.13 & 30.3 & 6.5 & \\
\hline & & 30.6 & 50 & 46.31 & 30.5 & 6.6 & \\
\hline & & 32.4 & 43 & 47.50 & 31.3 & 6.8 & \\
\hline & & 33.8 & 35 & 46.73 & 30.3 & 6.1 & \\
\hline & \multirow[t]{6}{*}{28 Aug 00} & 15.0 & 316 & 39.71 & 20.5 & 0.0 & $*$ \\
\hline & & 17.1 & 315 & 41.80 & 22.3 & 0.7 & \\
\hline & & 18.7 & 282 & 41.97 & 21.4 & -0.3 & \\
\hline & & 20.9 & 209 & 42.92 & 25.0 & 2.9 & \\
\hline & & 22.7 & 192 & 43.23 & 25.4 & 3.1 & \\
\hline & & 25.8 & 144 & 44.13 & 27.1 & 4.4 & \\
\hline & \multirow[t]{5}{*}{30 May 01} & 14.9 & 300 & 41.22 & 21.7 & 0.4 & \\
\hline & & 16.8 & 292 & 41.04 & 21.7 & 0.5 & \\
\hline & & 18.8 & 280 & 40.02 & 20.5 & -0.2 & \\
\hline & & 27.6 & 154 & 42.58 & 25.4 & 3.4 & \\
\hline & & 29.4 & 107 & 44.03 & 27.7 & 5.0 & \\
\hline & \multirow[t]{9}{*}{4 Sep 02} & 15.2 & 316 & 42.24 & 21.6 & -0.2 & $*$ \\
\hline & & 16.4 & 315 & 40.44 & 20.8 & -0.1 & $*$ \\
\hline & & 18.7 & 296 & 42.15 & 23.1 & 1.3 & \\
\hline & & 20.6 & 231 & 43.16 & 25.1 & 2.8 & \\
\hline & & 22.9 & 210 & 43.90 & 26.7 & 4.1 & \\
\hline & & 24.0 & 208 & 43.19 & 26.0 & 3.7 & \\
\hline & & 27.7 & 95 & 44.79 & 28.2 & 5.1 & \\
\hline & & 30.3 & 50 & 45.68 & 30.5 & 6.9 & \\
\hline & & 34.0 & 19 & 47.08 & 31.2 & 6.9 & \\
\hline & \multirow[t]{11}{*}{6 Sep 04} & 14.7 & 318 & 41.63 & 21.4 & -0.1 & $*$ \\
\hline & & 16.5 & 317 & 42.11 & 22.2 & 0.5 & \\
\hline & & 18.7 & 287 & 42.27 & 22.3 & 0.5 & \\
\hline & & 21.2 & 238 & 42.90 & 24.9 & 2.7 & \\
\hline & & 23.4 & 183 & 43.79 & 25.1 & 2.5 & \\
\hline & & 25.7 & 180 & 43.55 & 25.0 & 2.5 & \\
\hline & & 27.8 & 124 & 43.64 & 27.3 & 4.7 & \\
\hline & & 30.5 & 53 & 45.11 & 29.1 & 5.8 & \\
\hline & & 31.5 & 30 & 46.47 & 30.8 & 6.8 & \\
\hline & & 32.8 & 30 & 46.61 & 31.6 & 7.6 & \\
\hline & & 35.6 & 16 & 46.90 & 31.3 & 7.1 & \\
\hline \multirow{11}{*}{$\begin{array}{l}\text { Kiruna } \\
\left(68^{\circ} \mathrm{N}\right)\end{array}$} & \multirow[t]{11}{*}{22 Feb 97} & 10.2 & 300 & 43.67 & 22.6 & 0.0 & $*$ \\
\hline & & 13.0 & 273 & 42.07 & 22.9 & 1.2 & \\
\hline & & 14.1 & 259 & 42.21 & 23.8 & 2.1 & \\
\hline & & 15.9 & 198 & 43.23 & 24.0 & 1.7 & \\
\hline & & 16.4 & 175 & 43.63 & 25.6 & 3.1 & \\
\hline & & 17.2 & 171 & 43.79 & 25.4 & 2.8 & \\
\hline & & 18.2 & 164 & 43.82 & 25.8 & 3.2 & \\
\hline & & 20.1 & 124 & 45.62 & 27.4 & 3.9 & \\
\hline & & 21.8 & 76 & 45.58 & 29.4 & 5.9 & \\
\hline & & 23.6 & 25 & 48.34 & 33.6 & 8.7 & \\
\hline & & 25.6 & 9 & 52.49 & 39.3 & 12.2 & \# \\
\hline
\end{tabular}


After 2001, we changed the sample storage method. Aliquots of the whole-air samples were transferred directly into preevacuated $1000 \mathrm{~cm}^{3}$ stainless steel gas canisters at a positive pressure of $2 \mathrm{~atm}$ without $\mathrm{CO}_{2}$ separation. They were stored for more than three years before analyses. It is noteworthy that the quality of our whole-air sampling and handling procedures was verified by concurrent analyses of multiple compositions, such as concentrations of $\mathrm{CO}_{2}, \mathrm{~N}_{2} \mathrm{O}$, and $\mathrm{CH}_{4}$, and $\delta^{13} \mathrm{C}_{\mathrm{CO}_{2}}$. The sample air was regarded as defective and eliminated from this study when an apparent anomaly was observed in any chemical or isotope signature.

\subsection{Oxygen isotope analysis using CF-IRMS}

Both $\delta^{18} \mathrm{O}_{\mathrm{CO}_{2}}$ and $\delta^{17} \mathrm{O}_{\mathrm{CO}_{2}}$ values of the stratospheric $\mathrm{CO}_{2}$ were analyzed simultaneously using a new continuous flowisotope ratio mass spectrometry (CF-IRMS) technique. Details of the analytical method and $\delta^{17} \mathrm{O}$ calculation were reported in Kawagucci et al. (2005). Herein, we describe them briefly. The $\mathrm{CO}_{2}$ and other molecules in a sample gas are separated using gas chromatography with helium as the carrier gas. After separation, $\mathrm{CO}_{2}$ is split and analyzed on-line using two procedures: 1) direct introduction into the IRMS (Finnigan MAT252) for isotope analysis, and 2) eliminating the ${ }^{17} \mathrm{O}$ anomaly in the $\mathrm{CO}_{2}$ by exchanging the oxygen atoms with high-temperature $\mathrm{CuO}$, with subsequent isotope analysis using IRMS. This CF-IRMS measurement yield two isotope values for "raw" $\mathrm{CO}_{2}$ and "exchanged" $\mathrm{CO}_{2}$ and results in four isotope ratios of $45 / 44_{\text {raw }}$, $46 / 44_{\text {raw }}, 45 / 44_{\mathrm{ex}}$, and $46 / 44_{\mathrm{ex}}$. The $\delta^{17} \mathrm{O}$ value is calculable accurately using these measured isotope ratios and several constants of $\lambda=0.516$ (Santrock et al., 1985), $K=0.0099235$ (Santrock et al., 1985), ${ }^{13} \mathrm{R}_{\mathrm{VPDB}}=0.0112372$ (Craig, 1957), and ${ }^{18} \mathrm{R}_{\text {VSMOW }}=0.0020052$ (Baertschi, 1976). The total analytical errors of this method in determining $\delta^{18} \mathrm{O}_{\mathrm{CO}_{2}}$, $\delta^{17} \mathrm{O}_{\mathrm{CO}_{2}}$, and $\Delta{ }^{17} \mathrm{O}_{\mathrm{CO}_{2}}$ values are estimated respectively as, at most, $\pm 0.05 \%$ o, $\pm 0.5 \%$, and $\pm 0.5 \%$. The $\mathrm{N}_{2} \mathrm{O}$ mixing ratio was also determined using a gas chromatographic technique with analytical precision of 2 ppbv using another aliquot from the same stratospheric air sample (Aoki et al., 2003).

\section{Results and discussion}

\subsection{Spatial distribution of $\Delta{ }^{17} \mathrm{O}_{\mathrm{CO}_{2}}$}

We obtained 53 whole stratospheric air samples and five tropospheric air samples during seven launches over Sanriku and Kiruna (Table 1). Figure 1 portrays altitude profiles of $\Delta{ }^{17} \mathrm{O}_{\mathrm{CO}_{2}}$ for each balloon launch. The ${ }^{17} \mathrm{O}$ anomalies reached maximum values of $+7.6 \%$ and $+12.2 \%$, respectively, over Sanriku and Kiruna. For comparison, similar altitude profiles reported in the previous studies are presented in that figure as well (Thiemens et al., 1995b; Alexander et al., 2001; Lämmerzahl et al., 2002).

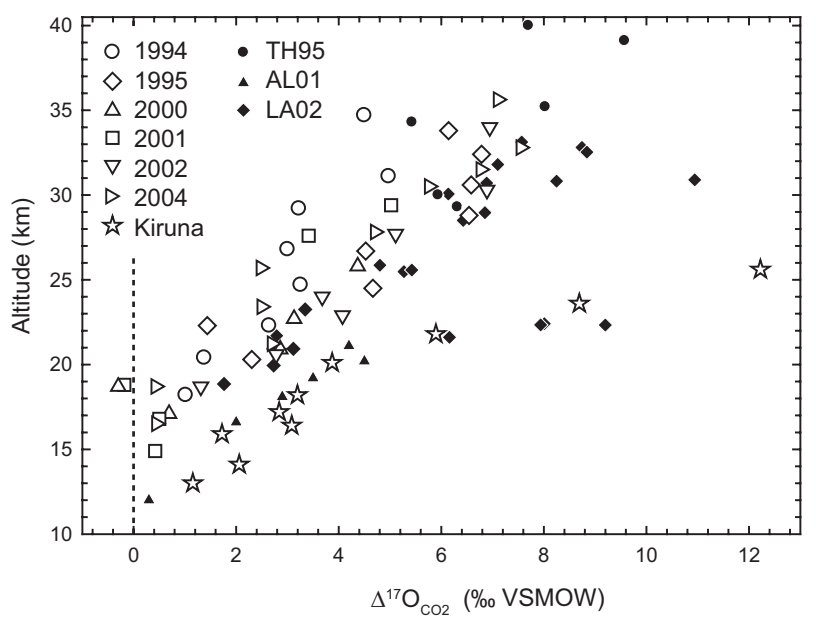

Fig. 1. Vertical profiles of $\Delta^{17} \mathrm{O}_{\mathrm{CO}_{2}}$. Open symbols represent our observation over Sanriku (categorized by the sampling year) and Kiruna. Filled symbols represent observations referred from previous studies: TH95 (Thiemens et al., 1995b), AL01 (Alexander et al., 2001), and LA02 (Lämmerzahl et al., 2002). A vertical dotted line indicates no ${ }^{17} \mathrm{O}$ anomaly.

The measurements over Sanriku revealed a nearly linear altitude dependence of $\Delta^{17} \mathrm{O}_{\mathrm{CO}_{2}}$. Some deviations from the linearity might reflect dynamic variation in the stratosphere. The vertical distribution of $\Delta^{17} \mathrm{O}_{\mathrm{CO}_{2}}$ over Kiruna exhibited a different profile: ${ }^{17} \mathrm{O}$ anomalies higher than $20 \mathrm{~km}$ height increased more quickly with increasing altitude than those lower than $20 \mathrm{~km}$ height, which agrees well with the results of previous studies of the stratosphere over Kiruna (Alexander et al., 2001; Lämmerzahl et al., 2002). In particular, large $\Delta{ }^{17} \mathrm{O}_{\mathrm{CO}_{2}}$ values $(>+5 \%$ ) even in the lower/middle stratosphere $(20-26 \mathrm{~km})$, observed in this study and by Lammerzahl et al. (2002), are noteworthy. The characteristic vertical profile of $\Delta^{17} \mathrm{O}_{\mathrm{CO}_{2}}$ over Kiruna resembles the typical one observed for long-lived tracers, such as $\mathrm{N}_{2} \mathrm{O}$ and $\mathrm{CH}_{4}$ mixing ratios within a polar vortex: Upper stratospheric and mesospheric air descends to the lower/middle stratosphere through strong downward advection (Waugh and Hall, 2002), resulting in upper stratospheric and mesospheric characteristics observed even in the lower/middle stratosphere. Indeed, $\Delta{ }^{17} \mathrm{O}_{\mathrm{CO}_{2}}$ at $25.6 \mathrm{~km}$ height in our observation over Kiruna reached $+12.2 \%$ (Table 1, Fig. 1), which is significantly greater than those over Sanriku at a similar height and which is as large as the highest value previously observed at $60 \mathrm{~km}$ height over New Mexico (Thiemens et al., 1995b). That result suggests the probable transport of a mesospheric air mass into the middle stratosphere over the Kiruna area.

\subsection{Triple oxygen isotopic compositions}

The triple oxygen isotopic compositions $\left(\delta^{18} \mathrm{O}_{\mathrm{CO}_{2}}\right.$ and $\left.\delta^{17} \mathrm{O}_{\mathrm{CO}_{2}}\right)$ determined in this study are depicted in Fig. 2. 
For comparison, those reported in other studies are shown in the figure as well (Thiemens et al., 1995b; Lammerzahl et al., 2002; Boering et al., 2004). A least-squares linear regression between $\delta^{18} \mathrm{O}_{\mathrm{CO}_{2}}$ and $\delta^{17} \mathrm{O}_{\mathrm{CO}_{2}}$ for the stratospheric samples (excluding five tropospheric samples) yields a slope of $1.63 \pm 0.10(2 \sigma)$ with a small deviation $\left(r^{2}>0.95\right.$; $n=53)$, which agrees with the slope $\left(1.71 \pm 0.06 ; r^{2}>0.99\right.$; $n=23$ ) observed previously in the lower/middle stratosphere (Lammerzahl et al., 2002) within combined 2-sigma errors. The agreement, or non-significant difference, of the slopes was further tested using statistical analysis, ANCOVA, with a 95\% confidence level $\left(F_{(1,72)}=0.87 ; p<0.05\right)$. We conclude that the slope on the triple oxygen isotope plot within mid-latitude lower/middle stratospheric $\mathrm{CO}_{2}$ (39$68^{\circ} \mathrm{N} ;<36 \mathrm{~km}$ ) is always constant for the observation term. In contrast, Thiemens et al. (1995b) reported a slope of $1.18 \pm 0.17\left(r^{2}>0.96 ; n=12\right)$ in their observation of both $\delta^{18} \mathrm{O}_{\mathrm{CO}_{2}}$ and $\delta^{17} \mathrm{O}_{\mathrm{CO}_{2}}$ values in upper stratospheric/lower mesospheric $\mathrm{CO}_{2}$, which is much lower than observations of the lower/middle stratosphere reported herein and by Lammerzahl et al. (2002). Furthermore, ANCOVA tests demonstrate significant differences in the regression between results reported by Thiemens et al. (1995b) and Lammerzahl et al. $(2002)\left(F_{(1,31)}=53.78 ; p>0.05\right)$ and between results of the former study and this study $\left(F_{(1,61)}=26.29 ; p>0.05\right)$.

The observed difference in the slopes implies that $\delta^{18} \mathrm{O}_{\mathrm{CO}_{2}}$ and $\delta{ }^{17} \mathrm{O}_{\mathrm{CO}_{2}}$ values might not have a simple linear relation, but rather an altitude-dependent difference by which the slopes become smaller as altitude increases (Kawagucci et al., 2005). Liang et al. (2007) also reported a gradual slope decline with increasing altitude using a theoretical model that incorporated a considerable impact of $\mathrm{O}_{2}$ photolysis to $\mathrm{O}\left({ }^{1} \mathrm{D}\right)$ in the mesosphere. Kawagucci et al. (2005) reported that the slopes in the $\delta^{18} \mathrm{O}_{\mathrm{CO}_{2}}$ and $\delta^{17} \mathrm{O}_{\mathrm{CO}_{2}}$ correlation line seem to be different for altitudes greater than and less than $25 \mathrm{~km}$ over Sanriku, although the difference was not statistically significant. Using the current dataset over Sanriku, which includes more data than reported in Kawagucci et al. (2005), the separate linear fit for the lower division $(<25 \mathrm{~km})$ yields a slightly larger slope of $1.60 \pm 0.13$ $\left(r^{2}>0.88 ; n=22\right)$ than that for the higher division $(>25 \mathrm{~km})$ of $1.46 \pm 0.11\left(r^{2}>0.90 ; n=21\right)$. However, ANCOVA tests for these slopes reveal no significant difference at a $95 \%$ confidence level $\left(F_{(1,39)}=0.71 ; p<0.05\right)$. In addition, a leastsquares quadratic fit for our stratospheric dataset showed a correlation coefficient of $r^{2}>0.95$, which is the same as that for a linear fit $\left(r^{2}>0.95\right)$, meaning that it is not possible to identify the gradual slope decline in the lower/middle stratosphere from our dataset. For those reasons, it is difficult to prove the gradual slope decline in the stratosphere, even from our dataset. Further observation of the triple oxygen isotopes in the upper stratosphere/lower mesosphere is necessary to prove the gradual decline in the slope.

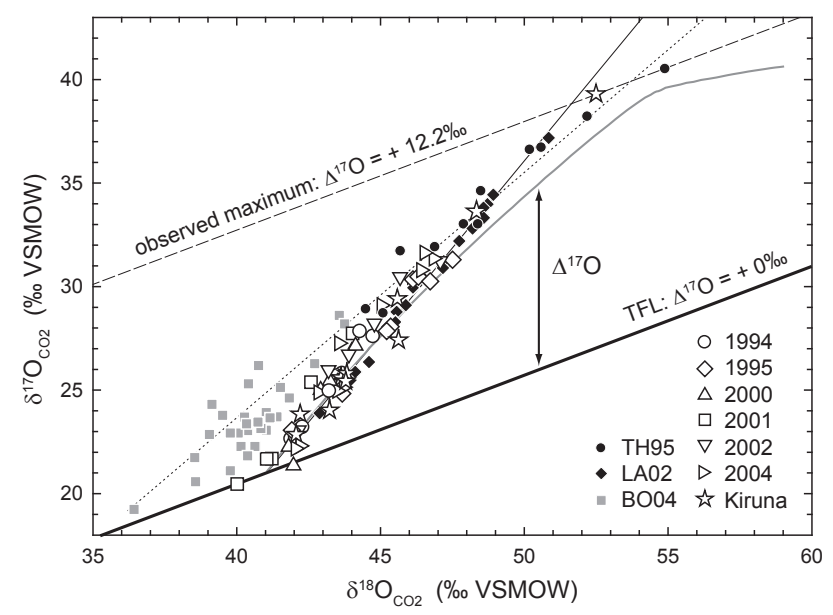

Fig. 2. $\delta^{18} \mathrm{O}_{\mathrm{CO}_{2}-}-\delta^{17} \mathrm{O}_{\mathrm{CO}_{2}}$ plot. Symbols are similar to those used for Fig. 1. Filled squares (BO04) represent datasets obtained from Boering et al. (2004). The terrestrial fractionation line (TFL: slope $=0.516)$ and also an isoclinic line for $\Delta^{17} \mathrm{O}_{\mathrm{CO}_{2}}=+12.2 \%$ that marks the maximum value of the atmospheric observations are shown respectively as a bold solid line and a dashed line. Thin solid and dotted lines respectively represent least square linear fits for our dataset and the dataset described by Thiemens et al. (1995b). A gray solid curve represents the model simulation result (from Fig. 5 in Liang et al., 2007) for comparison.

\subsection{Correlation between $\mathrm{N}_{2} \mathrm{O}$ mixing ratio and oxygen iso- topes in $\mathrm{CO}_{2}$}

The physical processes in the stratosphere that are responsible for the characteristic spatial distribution of $\Delta^{17} \mathrm{O}_{\mathrm{CO}_{2}}$ in both Sanriku and Kiruna (Fig. 1) can be studied by plotting $\Delta{ }^{17} \mathrm{O}_{\mathrm{CO}_{2}}$ against the $\mathrm{N}_{2} \mathrm{O}$ mixing ratio (Boering et al., 2004). The present data, except for the five tropospheric samples and the sample showing the largest ${ }^{17} \mathrm{O}$ anomaly of $+12.2 \%$ over Kiruna (Table 1), exhibited a linear negative correlation between $\Delta{ }^{17} \mathrm{O}_{\mathrm{CO}_{2}}$ and $\mathrm{N}_{2} \mathrm{O}$ mixing ratio $\left(r^{2}>0.90\right)$ (Fig. 3a), with some deviations from the fit line which are larger than the analytical errors. The linear correlation suggests that the relative reaction rates between the heavy oxygen isotope accumulation in $\mathrm{CO}_{2}(\mathrm{R} 1-\mathrm{R} 2)$ and photochemical $\mathrm{N}_{2} \mathrm{O}$ destruction are almost uniform in the lower and middle stratosphere. On the other hand, the sample showing the largest ${ }^{17} \mathrm{O}$ anomaly of $+12.2 \%$ in the middle stratosphere over Kiruna (Table 1, Fig. 1) deviates from the general linear correlation of $\mathrm{N}_{2} \mathrm{O}-\Delta^{17} \mathrm{O}_{\mathrm{CO}_{2}}$ (Fig. 3a). It overlaps with the values from the mesosphere (Thiemens et al., 1995b), suggesting its mesosphere origin, as discussed above. In addition to $\Delta^{17} \mathrm{O}_{\mathrm{CO}_{2}}, \delta^{18} \mathrm{O}_{\mathrm{CO}_{2}}$ showed a negative linear correlation with the $\mathrm{N}_{2} \mathrm{O}$ mixing ratio (Fig. 3b), as presented in Aoki et al. (2003). Deviations comparable to those in the $\mathrm{N}_{2} \mathrm{O}-\Delta{ }^{17} \mathrm{O}_{\mathrm{CO}_{2}}$ correlation were also observed in the $\mathrm{N}_{2} \mathrm{O}-\delta^{18} \mathrm{O}_{\mathrm{CO}_{2}}$ correlation, although the degree of the deviations was much smaller than for those described in Boering et al. (2004) (Fig. 3). 


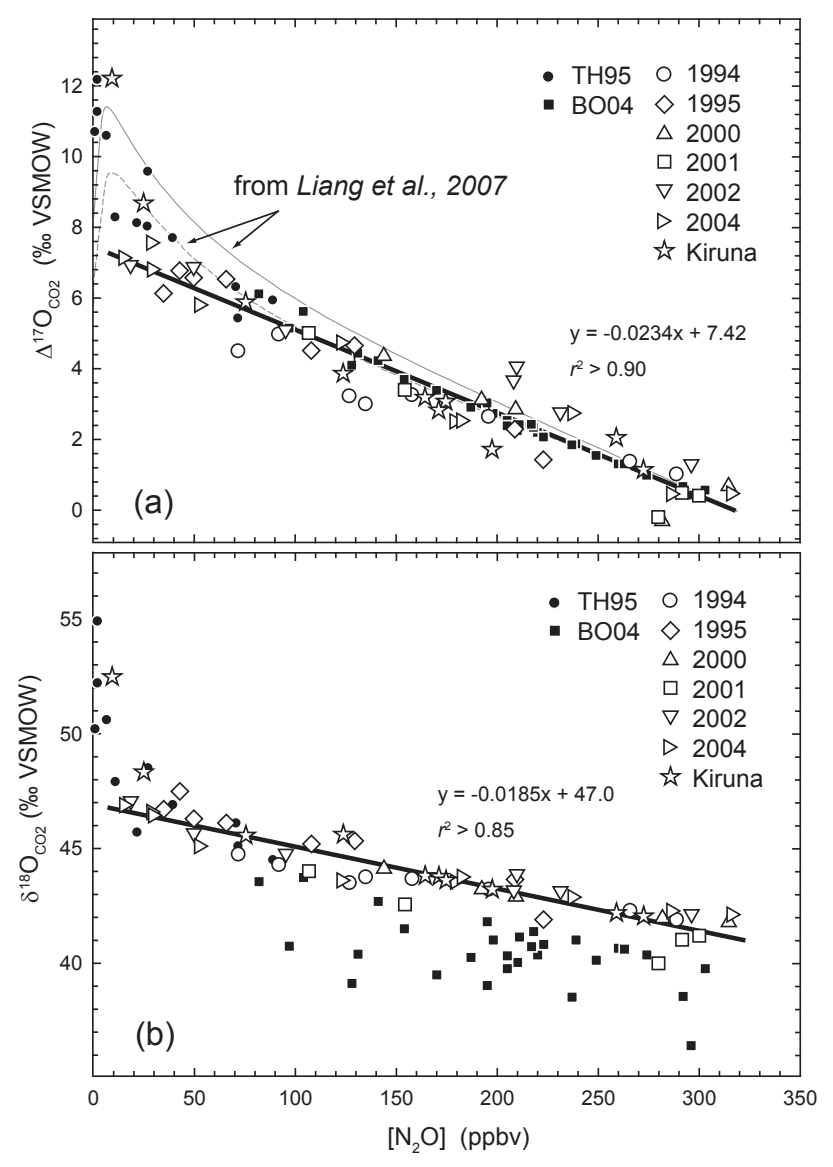

Fig. 3. $\mathrm{N}_{2} \mathrm{O}$ mixing ratio and (a) $\Delta^{17} \mathrm{O}_{\mathrm{CO}_{2}}$ or (b) $\delta^{18} \mathrm{O}_{\mathrm{CO}_{2}}$ plots. Symbols are the same as those shown in Figs. 1 and 2. Solid bold lines represent linear square regression lines for our stratospheric observation, excluding a sample showing $\Delta^{17} \mathrm{O}_{\mathrm{CO}_{2}}=+12.2 \%$ and $\delta^{18} \mathrm{O}_{\mathrm{CO}_{2}}=+52.49 \%$, used for isotope flux estimations. Solid and dash curves in Fig. 3a represent model simulation results referred from Liang et al. (2007).

The observed deviations from the linear correlations in the plots of $\mathrm{N}_{2} \mathrm{O}-\Delta^{17} \mathrm{O}_{\mathrm{CO}_{2}}$ and $\mathrm{N}_{2} \mathrm{O}-\delta^{18} \mathrm{O}_{\mathrm{CO}_{2}}$ could reflect either some changes in the major natural (photo)chemical processes in the stratosphere, in which the relative destruction rate of $\mathrm{N}_{2} \mathrm{O}$ against the heavy oxygen isotope accumulation rate in $\mathrm{CO}_{2}$ (R1-R2) have varied, or some additional isotope fractionation processes for $\mathrm{CO}_{2}$ other than the Reactions (R1)-(R2). The $\mathrm{N}_{2} \mathrm{O}$ destruction rate is almost entirely ( $\sim 90 \%)$ governed by UV radiation, although the accumulation rate of heavy oxygen isotopes in $\mathrm{CO}_{2}(\mathrm{R} 2)$ is controlled by the $\mathrm{O}\left({ }^{1} \mathrm{D}\right)$ concentration governed by both the $\mathrm{O}_{3}$ concentration and its photolysis rate (R1a). Therefore, independent changes in the reaction rates in response to variations in stratospheric chemical conditions, such as abundances of $\mathrm{O}_{3}$ and $\mathrm{O}\left({ }^{1} \mathrm{D}\right)$ that would control the accumulation rate with no relation to $\mathrm{N}_{2} \mathrm{O}$ destruction, for example, might cause deviation from linear $\mathrm{N}_{2} \mathrm{O}-\Delta^{17} \mathrm{O}_{\mathrm{CO}_{2}}$ and $\mathrm{N}_{2} \mathrm{O}-\delta^{18} \mathrm{O}_{\mathrm{CO}_{2}}$ corre-

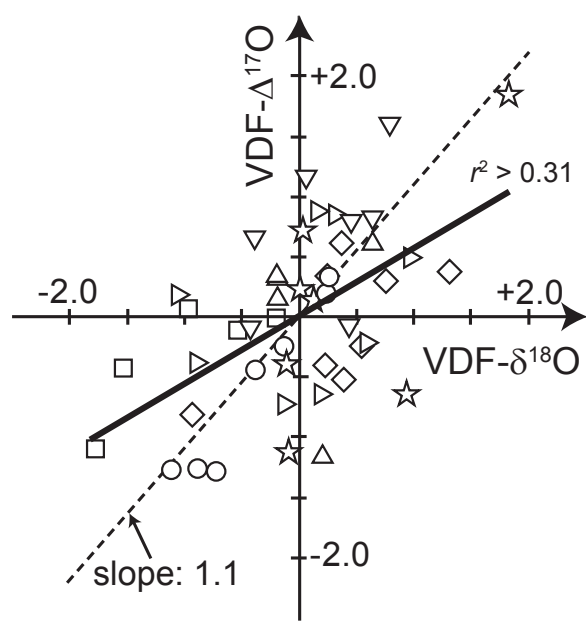

Fig. 4. A correlation plot between VDF- $\delta^{18} \mathrm{O}$ and VDF- $\Delta{ }^{17} \mathrm{O}$. Symbols are the same as those used for Fig. 1. A solid line is leastsquares fitting line. A dashed line denotes a theoretical line with a slope of 1.1 .

lation. However, isotope fractionation processes other than the (R1)-(R2) reactions, most of which fractionate under the mass-dependent relation that is usual for almost all physical and chemical processes (e.g. Thiemens et al., 1999), cause changes only in the $\mathrm{N}_{2} \mathrm{O}-\delta^{18} \mathrm{O}_{\mathrm{CO}_{2}}$ correlation. Consequently, a comparison of the deviations between the $\mathrm{N}_{2} \mathrm{O}-\Delta^{17} \mathrm{O}_{\mathrm{CO}_{2}}$ and $\mathrm{N}_{2} \mathrm{O}-\delta^{18} \mathrm{O}_{\mathrm{CO}_{2}}$ correlations is useful to examine potential additional isotope fractionation processes. For this purpose, we introduce new parameters, VDF- $\Delta{ }^{17} \mathrm{O}$ and VDF- $\delta^{18} \mathrm{O}$, which correspond to the vertical deviation of each datum from the fit lines of either $\mathrm{N}_{2} \mathrm{O}-\Delta{ }^{17} \mathrm{O}_{\mathrm{CO}_{2}}$ or $\mathrm{N}_{2} \mathrm{O}-\delta^{18} \mathrm{O}_{\mathrm{CO}_{2}}$ plot (Fig. 3) using the following equations:

$$
\begin{aligned}
& \text { VDF- } \Delta{ }^{17} \mathrm{O}=\Delta \Delta^{17} \mathrm{O}_{\mathrm{CO}_{2}}-\left(-0.0234 \times\left[\mathrm{N}_{2} \mathrm{O}\right]+7.42\right) \\
& \text { VDF- } \delta{ }^{18} \mathrm{O}=\delta^{18} \mathrm{O}_{\mathrm{CO}_{2}}-\left(-0.0185 \times\left[\mathrm{N}_{2} \mathrm{O}\right]+47.0\right)
\end{aligned}
$$

Calculated VDF values for stratospheric samples are within $\pm 2 \%$, as presented in Fig. 4, although the VDF values for the sample showing the largest ${ }^{17} \mathrm{O}$ anomaly of $+12.2 \%$ o are out of that range $(>+5 \%)$, indicating a distinguishable origin as discussed above. By plotting VDF- $\Delta{ }^{17} \mathrm{O}$ against VDF- $\delta^{18} \mathrm{O}$, we can distinguish whether those deviations are explainable according to changes in the relative destruction rate of $\mathrm{N}_{2} \mathrm{O}$ or not. That is to say, if the relative reaction rate change were the only process responsible for the deviations, the correlation between the VDF- $\delta^{18} \mathrm{O}$ and VDF- $\Delta{ }^{17} \mathrm{O}$ values would be expected to be linear with a slope of +1.1-1.2 (Fig. 4), as calculated from the constant fractionation slope of +1.6-1.7 between $\delta^{18} \mathrm{O}_{\mathrm{CO}_{2}}$ and $\delta^{17} \mathrm{O}_{\mathrm{CO}_{2}}$ (Fig. 2) and the $\Delta{ }^{17} \mathrm{O}$ definition of $\Delta^{17} \mathrm{O}=\delta^{17} \mathrm{O}-0.516 \times \delta^{18} \mathrm{O}$. Although the observed VDF- $\Delta^{17} \mathrm{O}$ values exhibit a correlation with the VDF- $\delta^{18} \mathrm{O}$ values, showing a positive slope of +0.6 (Fig. 4), the linearity is not good $\left(r^{2}>0.31\right)$. Therefore, we conclude 
that, aside from changes in the relative reaction rate in the stratosphere that produce the slope of $+1.1-1.2$, some additional isotope fractionation processes having different slopes on the plot between the VDF values, such as the slope of 0 (mass-dependent fractionation processes), were involved in the observed isotopic compositions of $\mathrm{CO}_{2}$ as well.

One such additional isotope fractionation process is, unfortunately, sample alteration during sampling and storage despite careful handling. For example, oxygen isotope exchange with stratospheric $\mathrm{H}_{2} \mathrm{O}$, which includes highly ${ }^{18} \mathrm{O}$ depleted $\delta^{18} \mathrm{O}$ from $\mathrm{CO}_{2}$ (Johnson et al., 2001), that takes place in canisters reduces $\delta^{18} \mathrm{O}_{\mathrm{CO}_{2}}$ values, with little accompanying $\Delta{ }^{17} \mathrm{O}_{\mathrm{CO}_{2}}$ variation (Boering et al., 2004). In this case, the maximum extent of $\delta^{18} \mathrm{O}$ change can be estimated as $1.5 \%$ from Fig. 4. That is to say, we can obtain linear correlation of the slope of 1.1-1.2 on the plot between VDF$\delta^{18} \mathrm{O}$ and VDF- $\Delta{ }^{17} \mathrm{O}$, by adding, at most, $1.5 \%$ o correction on VDF- $\delta^{18} \mathrm{O}$. Therefore, we adopt the value for the maximum extent of errors in $\delta^{18} \mathrm{O}_{\mathrm{CO}_{2}}$ for subsequent discussions.

\subsection{Net oxygen isotope flux to the troposphere}

The linear correlations of $\Delta{ }^{17} \mathrm{O}_{\mathrm{CO}_{2}}$ and $\delta^{18} \mathrm{O}_{\mathrm{CO}_{2}}$ with the $\mathrm{N}_{2} \mathrm{O}$ mixing ratio enable us to quantify net isotope fluxes of $\Delta^{17} \mathrm{O}$ and $\delta^{18} \mathrm{O}$ in $\mathrm{CO}_{2}$ from the stratosphere to the troposphere. A slope of the fitting line between two longlived tracers is known to be equal to the ratio of their net vertical fluxes (Plumb and Ko, 1992); furthermore, the net vertical flux of $\mathrm{N}_{2} \mathrm{O}$ is estimated as the global $\mathrm{N}_{2} \mathrm{O}$ loss rate of $13 \mathrm{MtN} / \mathrm{yr}$ with uncertainty of $\pm 25 \%$ (Prather and Ehhalt, 2001). Using the dataset in the stratosphere (excluding five tropospheric and one mesosphere-derived samples)(Table 1), least-squares linear fitting is applied to correlation plots of $\mathrm{N}_{2} \mathrm{O}-\Delta^{17} \mathrm{O}_{\mathrm{CO}_{2}}$ and $\mathrm{N}_{2} \mathrm{O}-\delta^{18} \mathrm{O}_{\mathrm{CO}_{2}}$. The fittings yielded slopes of $-0.0234 \pm 0.0022\left(\% / \mathrm{ppbv}, r^{2}>0.90\right)$ and $-0.0185 \pm 0.0022\left(\% / \mathrm{ppbv}, r^{2}>0.85\right.$ ), respectively, for $\mathrm{N}_{2} \mathrm{O}-\Delta{ }^{17} \mathrm{O}_{\mathrm{CO}_{2}}$ and $\mathrm{N}_{2} \mathrm{O}-\delta^{18} \mathrm{O}_{\mathrm{CO}_{2}}$. The best fit lines are shown as solid lines with the formulas presented in Fig. 3a and $b$. Assuming that the $\mathrm{CO}_{2}$ mixing ratio in the stratosphere during our observation period is constant ( $370 \mathrm{ppmv})$, the resulting net isotope fluxes of $\Delta^{17} \mathrm{O}_{\mathrm{CO}_{2}}$ and $\delta^{18} \mathrm{O}_{\mathrm{CO}_{2}}$ are estimated as $+48 \%$ o $\mathrm{GtC} / \mathrm{yr}$ and $+38 \%$ o $\mathrm{GtC} / \mathrm{yr}$, respectively. We estimate that the calculated isotope fluxes might include $\sim 30 \%$ uncertainty because of the uncertainty in the estimated $\mathrm{N}_{2} \mathrm{O}$ loss rate used here, uncertainty in the least-squares linear fitting, and the assumption of a constant $\mathrm{CO}_{2}$ mixing ratio. The isotope flux of $\Delta^{17} \mathrm{O}_{\mathrm{CO}_{2}}$ estimated in this study resembles that reported by Boering et al. (2004).

\subsection{Comparison of current observation and model calcula- tion}

Liang et al. (2007) first investigated the considerable contribution of $\mathrm{O}_{2}$ photolysis in the upper mesosphere to the oxygen isotope composition of middle atmospheric $\mathrm{CO}_{2}$.
They simulated correlation of $\mathrm{N}_{2} \mathrm{O}-\Delta^{17} \mathrm{O}_{\mathrm{CO}_{2}}$ and $\delta^{18} \mathrm{O}_{\mathrm{CO}_{2}}{ }^{-}$ $\delta^{17} \mathrm{O}_{\mathrm{CO}_{2}}$ using a $1 \mathrm{D}$ vertical model. That innovative model, however, has not been tested yet, especially in terms of its adequacy for assessing effects of $\mathrm{O}_{2}$ photolysis on $\mathrm{CO}_{2}$. Herein, we verify the theory in Liang's model to compare the simulation results with the observation results. The simulation results are included in the current correlation plots of $\delta^{18} \mathrm{O}_{\mathrm{CO}_{2}}-\delta^{17} \mathrm{O}_{\mathrm{CO}_{2}}$ and $\mathrm{N}_{2} \mathrm{O}-\Delta{ }^{17} \mathrm{O}_{\mathrm{CO}_{2}}$ portrayed in Figs. 2 and $3 \mathrm{a}$, for which two different eddy diffusion constants were used for comparison (original values: solid curves in Figs. 2 and 3a; increased by $30 \%$ for altitudes of less than $40 \mathrm{~km}$ : dashed curve only in Fig. 3a) (see Liang et al., 2007).

On the $\delta^{18} \mathrm{O}_{\mathrm{CO}_{2}}-\delta^{17} \mathrm{O}_{\mathrm{CO}_{2}}$ plot (Fig. 2), the slope of the solid curve shows good fit for the lower stratosphere, but it declines gradually and underestimates $\Delta^{17} \mathrm{O}_{\mathrm{CO}_{2}}$ concomitantly with increasing altitude (increasing $\delta^{18} \mathrm{O}_{\mathrm{CO}_{2}}$ ) in the model (Fig. 2) in comparison to observations from various latitudes and altitudes (Thiemens et al., 1995b; Lammerzahl et al., 2002; this study). In particular, the maximum $\Delta^{17} \mathrm{O}_{\mathrm{CO}_{2}}$ value in the simulation result, which corresponds to ca. $55 \mathrm{~km}$ height, does not reach that in the observation results (isoclinic line in Fig. 2). Furthermore, on the $\mathrm{N}_{2} \mathrm{O}-$ $\Delta^{17} \mathrm{O}_{\mathrm{CO}_{2}}$ plot, the change of the eddy diffusion constant from the original value (solid curve) to the increased value (dashed curve) results in an excellent fit between the model and observation at a range of $\left[\mathrm{N}_{2} \mathrm{O}\right]>\sim 50 \mathrm{ppbv}$, corresponding to the lower/middle stratosphere, although the discrepancy in the maximum $\Delta{ }^{17} \mathrm{O}_{\mathrm{CO}_{2}}$ values between the model and observation is more significant. The cause of the underestimation of the maximum $\Delta{ }^{17} \mathrm{O}_{\mathrm{CO}_{2}}$ in the model will be discussed later. In addition to that disagreement, at a range of $\left[\mathrm{N}_{2} \mathrm{O}\right]<\sim 50 \mathrm{ppbv}$, the observation result over Sanriku demonstrates smaller ${ }^{17} \mathrm{O}$ anomalies in $\mathrm{CO}_{2}$ compared to the model simulation result. The wide ranges of the observed $\Delta{ }^{17} \mathrm{O}_{\mathrm{CO}_{2}}$ values at the range of $\left[\mathrm{N}_{2} \mathrm{O}\right]<\sim 50 \mathrm{ppbv}$ would be informative for middle/upper stratospheric chemistry and physics, although only a fragmentary dataset of chemical and isotopic compositions in the middle/upper stratosphere is available for comparison to those in the lower/middle stratosphere $\left(\left[\mathrm{N}_{2} \mathrm{O}\right]>\mathrm{ca}\right.$. $\left.50 \mathrm{ppbv}\right)$. Additional intensive observation throughout the whole stratosphere will elucidate the complex chemistry and air transport in the upper stratosphere.

Oxygen isotope fractionation in middle atmospheric $\mathrm{CO}_{2}$ occurs through isotope exchange between $\mathrm{CO}_{2}$ and $\mathrm{O}\left({ }^{1} \mathrm{D}\right)$ produced by photolysis of $\mathrm{O}_{3}$ and $\mathrm{O}_{2}$ (Yung et al., 1991; Liang et al., 2007). The possibility of oxygen isotope fractionation from the $\mathrm{CO}_{2}$ photodissociation reaction has also been proposed (Bhattacharya et al., 2000), although the actual contribution of the isotope fractionation was considered to be negligible throughout the middle atmosphere (Liang et al., 2007). Oxygen isotope fractionation in the series of reactions of $\mathrm{CO}_{2}$ with $\mathrm{O}\left({ }^{1} \mathrm{D}\right)$ through photolysis of $\mathrm{O}_{3}(\mathrm{R} 1 \mathrm{a}-\mathrm{R} 2)$, which dominates in the stratosphere, engenders a steep slope of $\sim 1.7$, as observed in the lower/middle stratospheric $\mathrm{CO}_{2}$ 
(Fig. 2). This engenders the strengthening ${ }^{17} \mathrm{O}$ anomaly with increasing altitude. On the other hand, Liang et al. (2007) pointed out that photolysis of $\mathrm{O}_{2}$ might dominate $\mathrm{O}\left({ }^{1} \mathrm{D}\right)$ production in the upper mesosphere and that the three isotope slopes of the Reactions (R1b)-(R2) in this region might be as low as 0.3. Consequently, $\Delta{ }^{17} \mathrm{O}_{\mathrm{CO}_{2}}$ will decrease again with increasing altitude if this pattern pertains in the upper mesosphere (Figs. 2 and 3a). Therefore, we conclude herein that the underestimation of maximum $\Delta^{17} \mathrm{O}_{\mathrm{CO}_{2}}$ value (Figs. 2 and 3a) in the model simulation implies some problems related to the treatment of $\mathrm{O}_{2}$ photolysis (R1b-R2) in the model. A possible reason is overestimation of the contribution of $\mathrm{O}_{2}$ photolysis in the model. In this case, changing the parameters in the model would yield a better fit of the simulated with the observed data without changing the underlying theory of the model.

\section{Concluding remarks}

Decade-long observations of triple oxygen isotope composition in stratospheric $\mathrm{CO}_{2}$ over Sanriku and Kiruna within the polar vortex revealed the following:

1. Observed $\delta^{18} \mathrm{O}_{\mathrm{CO}_{2}}$ and $\delta^{17} \mathrm{O}_{\mathrm{CO}_{2}}$ showed a good linear correlation $\left(r^{2}>0.95\right)$ with a slope of $1.63 \pm 0.10(2 \sigma)$, which is consistent with that observed in the middlelatitude lower/middle stratosphere (Lammerzahl et al., 2002). However, it differs clearly from that observed in the upper stratosphere/lower mesosphere (Thiemens et al., 1995b). The reason for the difference in the slopes remains unknown.

2. Both $\mathrm{N}_{2} \mathrm{O}-\Delta^{17} \mathrm{O}_{\mathrm{CO}_{2}}$ and $\mathrm{N}_{2} \mathrm{O}-\delta^{18} \mathrm{O}_{\mathrm{CO}_{2}}$ plots showed a negative linear correlation, as previously reported respectively by Boering et al. (2004) and Aoki et al. (2003). Based on those linear relations, $\mathrm{CO}_{2}$ oxygen isotope fluxes from the stratosphere to the troposphere are estimated as $+48 \%$ GtC/yr $\left(\Delta^{17} \mathrm{O}_{\mathrm{CO}_{2}}\right)$ and $+38 \%$ o $\mathrm{GtC} / \mathrm{yr}\left(\delta^{18} \mathrm{O}_{\mathrm{CO}_{2}}\right)$ with $\sim 30 \%$ uncertainties.

3. A comparison between a recent model study and observations revealed underestimation of the maximum $\Delta{ }^{17} \mathrm{O}_{\mathrm{CO}_{2}}$ value in the model. One reason might be overestimation of $\mathrm{O}_{2}$ photolysis considered in the model.

Results of the current study show that long-term observations of $\delta^{18} \mathrm{O}_{\mathrm{CO}_{2}}, \delta^{17} \mathrm{O}_{\mathrm{CO}_{2}}$, and $\mathrm{N}_{2} \mathrm{O}$ mixing ratios are informative when combined with a model study that particularly addresses correlations of $\mathrm{N}_{2} \mathrm{O}-\Delta{ }^{17} \mathrm{O}_{\mathrm{CO}_{2}}$ and $\delta^{18} \mathrm{O}_{\mathrm{CO}_{2}}$ $\delta^{17} \mathrm{O}_{\mathrm{CO}_{2}}$. These results can elucidate triple oxygen isotope fractionations in $\mathrm{CO}_{2}$ and help to untangle complex interactions among physical, chemical, and photochemical processes in the middle atmosphere.
Acknowledgements. We are grateful to the balloon-launching staff of the Japan Aerospace Exploration Agency and the Sanriku Balloon Center for sampling launches. We thank T. Röckmann and $\mathrm{K}$. Boering and an anonymous referee for their insightful comments, which were helpful to improve the manuscript. We also extend our appreciation to Hiroshi Furutani and Antra Pandey for their helpful comments to clarify the discussion and presentation. This research was supported by the following grants: MEXT Grants-in-Aid No. 20310003 and No. 18067001, the Global Environment Research Fund (RF-65) of the Ministry of the Environment, and a MEXT Grant-in-Aid for JSPS Fellows, 18.4415. S. K. was supported by Research Fellowships of the Japan Society for the Promotion of Science for Young Scientists (DC).

Edited by: T. Röckmann

\section{References}

Alexander, B., Vollmer, M. K., Jackson, T., Weiss, R. F., and Thiemens, M. H.: Stratospheric $\mathrm{CO}_{2}$ isotopic anomalies and $\mathrm{SF}_{6}$ and CFC tracer concentrations in the arctic polar vortex, Geophys. Res. Lett., 28, 4103-4106, 2001.

Aoki, S., Nakazawa, T., Machida, T., Sugawara, S., Morimoto, S., Hashida, G., Yamanouchi, T., Kawamura, K., and Honda, H.: Carbon dioxide variations in the stratosphere over Japan, Scandinavia and Antarctica, Tellus B, 55, 178-186, 2003.

Baertschi, P.: Absolute ${ }^{18} \mathrm{O}$ content of standard mean ocean water, Earth Planet. Sc. Lett., 31, 341-344, 1976.

Bhattacharya, S. K., Savarino, J., and Thiemens, M. H.: A new class of oxygen isotopic fractionation in photodissociation of carbon dioxide: Potential implications for atmospheres of Mars and Earth, Geophys. Res. Lett., 27, 1459-1462, 2000.

Boering, K. A., Jackson, T., Hoag, K. J., Cole, A. S., Perri, M. J., Thiemens, M., and Atlas, E.: Observations of the anomalous oxygen isotopic composition of carbon dioxide in the lower stratosphere and the flux of the anomaly to the troposphere, Geophys. Res. Lett., 31, L03109, doi:10.1029/2003GL018451, 2004.

Chakraborty, S. and Bhattacharya, S. K.: Experimental investigation of oxygen isotope exchange between $\mathrm{CO}_{2}$ and $\mathrm{O}\left({ }^{1} \mathrm{D}\right)$ and its relevance to the stratosphere, J. Geophys. Res.-Atmos., 108, 4724, doi:10.1029/2002JD002915, 2003.

Ciais, P., Denning, A. S., Tans, P. P., Berry, J. A., Randall, D. A., Collatz, G. J., Sellers, P. J., White, J. W. C., Trolier, M., Meijer, H. A. J., Francey, R. J., Monfray, P., and Heimann, M.: A threedimensional synthesis study of $\delta^{18} \mathrm{O}$ in atmospheric $\mathrm{CO}_{2}: 1$. Surface fluxes, J. Geophys. Res.-Atmos., 102, 5857-5872, 1997.

Craig, H.: Isotopic standards for carbon and oxygen and correction factors for mass-spectrometric analysis of carbon dioxide, Geochim. Cosmochim. Acta, 12, 133-149, 1957.

Cuntz, M., Ciais, P., Hoffmann, G., and Knorr, W.: A comprehensive global three-dimensional model of $\delta^{18} \mathrm{O}$ in atmospheric $\mathrm{CO}_{2}$ : 1. Validation of surface processes, J. Geophys. Res.Atmos., 108, 4528, doi:10.1029/2002JD003154, 2003.

Gamo, T., Tsutsumi, M., Sakai, H., Nakazawa, T., Tanaka, M., Honda, H., Kubo, H., and Itoh, T.: Carbon and oxygen isotopic ratios of carbon dioxide a stratospheric profile over Japan, Tellus, 41B, 127-133, 1989.

Gamo, T., Tsutsumi, M., Sakai, H., Nakazawa, T., Machida, T., Honda, H., and Itoh, T.: Long-term monitoring of carbon and 
oxygen-isotope ratios of stratospheric $\mathrm{CO}_{2}$ over Japan, Geophys. Res. Lett., 22, 397-400, 1995.

Hoag, K. J., Still, C. J., Fung, I. Y., and Boering, K. A.: Triple oxygen isotope composition of tropospheric carbon dioxide as a tracer of terrestrial gross carbon fluxes, Geophys. Res. Lett., 32, L02802, doi:10.1029/2004GL021011, 2005.

Honda, H., Aoki, S., Nakazawa, T., Morimoto, S., and Yajima, N.: Cryogenic air sampling system for measurements of the concentrations of stratospheric trace gases and their isotopic ratios over antarctica, J. Geomagn. Geoelectr., 48, 1145-1155, 1996.

Honda, H.: Research on balloon-borne whole air sampling system for studying stratospheric minor constituents, Bulletin of Institute of Space and Astronautical Science , 115, 1-93, 2001 (in Japanese with English abstract).

Kawagucci, S., Tsunogai, U., Kudo, S., Nakagawa, F., Honda, H., Aoki, S., Nakazawa, T., and Gamo, T.: An analytical system for determining $\delta^{17} \mathrm{O}$ in $\mathrm{CO}_{2}$ using continuous flow-isotope ratio MS, Anal. Chem., 77, 4509-4514, 2005.

Johnson, D. G., Jucks, K. W., Traub, W. A., and Chance, K. V.: Isotopic composition of stratospheric water vapor: Measurements and photochemistry, J. Geophys. Res.-Atmos., 106, 12 211-12 217, 2001.

Johnston, J. C., Röckmann, T., and Brenninkmeijer, C. A. M.: $\mathrm{CO}_{2}$ $+\mathrm{O}\left({ }^{1} \mathrm{D}\right)$ isotopic exchange: Laboratory and modeling studies, $\mathrm{J}$. Geophys. Res., 105, 15 213-15 229, 2000.

Lacoursiere, J., Meyer, S. A., Faris, G. W., Slanger, T. G., Lewis, B. R., and Gibson, S. T.: The $\mathrm{O}\left({ }^{1} \mathrm{D}\right)$ yield from $\mathrm{O}_{2}$ photodissociation near H Lyman-alpha (121.6 nm), J. Chem. Phys., 110, 1949-1958, 1999.

Lämmerzahl, P., Röckmann, T., Brenninkmeijer, C. A. M., Krankowsky, D., and Mauersberger, K.: Oxygen isotope composition of stratospheric carbon dioxide, Geophys. Res. Lett., 29, 1582, doi:10.1029/2001GL014343, 2002.

Liang, M. C., Blake, G. A., Lewis, B. R., and Yung, Y. L.: Oxygen isotopic composition of carbon dioxide in the middle atmosphere, Proceedings of the National Academy of Sciences of the United States of America, 104, 21-25, 2007.

Matsuhisa, Y., Goldsmith, J. R., and Clayton, R. N.: Mechanism of hydrothermal crystallization of quartz at $250^{\circ} \mathrm{C}$ and $15 \mathrm{kbar}$, Geochim. Cosmochim. Acta, 42, 173-182, 1978.

Mauersberger, K.: Ozone isotope measurements in the stratosphere, Geophys. Res. Lett., 14, 80-83, 1987.

Miller, M. F.: Isotopic fractionation and the quantification of ${ }^{17} \mathrm{O}$ anomalies in the oxygen three-isotope system: An appraisal and geochemical significance, Geochim. Cosmochim. Acta, 66, 1881-1889, 2002.

Miller, M. F., Röckmann, T., and Wright, I. P.: A general algorithm for the ${ }^{17} \mathrm{O}$ abundance correction to ${ }^{13} \mathrm{C} /{ }^{12} \mathrm{C}$ determinations from $\mathrm{CO}_{2}$ isotopologue measurements, including $\mathrm{CO}_{2}$ characterised by 'mass-independent' oxygen isotope distributions, Geochim. Cosmochim. Acta, 71, 3145-3161, 2007.
Nakazawa, T., Machida, T., Sugawara, S., Murayama, S., Morimoto, S., and Hashida, G.: Measurements of the stratospheric carbon-dioxide concentration over Japan using a balloon-borne cryogenic sampler, Geophys. Res. Lett., 22, 1229-1232, 1995.

Perri, M. J., Van Wyngarden, A. L., Boering, K. A., Lin, J. J., and Lee, Y. T.: Dynamics of the $\mathrm{O}\left({ }^{1} \mathrm{D}\right)+\mathrm{CO}_{2}$ oxygen isotope exchange reaction, J. Chem. Phys., 119, 8213-8216, 2003.

Plumb, R. A. and Ko, M. K. W.: Interrelationships between mixing ratios of long lived stratospheric constituents, J. Geophys. Res.Atmos., 97, 10 145-10 156, 1992.

Prather, M. J. and Ehhalt, D.: 3rd report of the Intergovernmental Panel on Climate Change, in: Climate Change, edited by: Houghton, J., et al., Cambridge Univ. Press, New York, 239-287, 2001.

Santrock, J., Studley, S. A., and Hayes, J. M.: Isotopic analyses based on the mass spectrum of carbon dioxide, Anal. Chem., 57, 1444-1448, 1985.

Shaheen, R., Janssen, C., and Rckmann, T.: Investigations of the photochemical isotope equilibrium between $\mathrm{O}_{2}, \mathrm{CO}_{2}$ and $\mathrm{O}_{3}$, Atmos. Chem. Phys., 7, 495-509, 2007, http://www.atmos-chem-phys.net/7/495/2007/.

Thiemens, M. H. and Heidenreich, J. E.: The mass-independent fractionation of oxygen - a novel isotope effect and its possible cosmochemical implications, Science, 219, 1073-1075, 1983.

Thiemens, M. H., Jackson, T., Mauersberger, K., Schueler, B., and Morton, J.: Oxygen isotope fractionation in stratospheric $\mathrm{CO}_{2}$, Geophys. Res. Lett., 18, 669-672, 1991.

Thiemens, M. H., Jackson, T. L., and Brenninkmeijer, C. A. M.: Observation of a mass-independent oxygen isotopic composition in terrestrial stratospheric $\mathrm{CO}_{2}$, the link to ozone chemistry, and the possible occurrence in the Martian atmosphere, Geophys. Res. Lett., 22, 255-257, 1995a.

Thiemens, M. H., Jackson, T., Zipf, E. C., Erdman, P. W., and van Egmond, C.: Carbon-dioxide and oxygen-isotope anomalies in the mesosphere and stratosphere, Science, 270, 969-972, 1995b.

Thiemens, M. H.: Mass-independent isotope effects in planetary atmospheres and the early solar system, Science, 283, 341-345, 1999.

Waugh, D. W. and Hall, T. M.: Age of stratospheric air: Theory, observations, and models, Rev. Geophys., 40, 1010, doi:10.1029/2000RG000101, 2002.

Wen, J. and M. H. Thiemens, Multi-isotope study of the $\mathrm{O}\left({ }^{1} \mathrm{D}\right)+$ $\mathrm{CO}_{2}$ exchange and stratospheric consequences, J. Geophys. Res., 98, 12 801-12 808, 1993.

Young, E. D., Galy, A., and Nagahara, H.: Kinetic and equilibrium mass-dependent isotope fractionation laws in nature and their geochemical and cosmochemical significance, Geochim. Cosmochim. Acta, 66, 1095-1104, 2002.

Yung, Y. L., Demore, W. B., and Pinto, J. P.: Isotopic exchange between carbon dioxide and ozone via $\mathrm{O}\left({ }^{1} \mathrm{D}\right)$ in the stratosphere, Geophys. Res. Lett., 18, 13-16, 1991. 